\title{
Revisiting the Australian/New Zealand Standard for Wind Actions (AS/NZS 1170.2:2011): Do current wind standards sufficiently capture local wind climates?
}

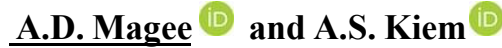 \\ Centre for Water, Climate and Land (CWCL), Faculty of Science, University of Newcastle, Australia \\ Email: andrew.magee@uon.edu.au
}

\begin{abstract}
The Australian/New Zealand Standard for Wind Actions (AS/NZS 1170.2:2011) provides advice on wind direction multipliers $\left(\mathrm{M}_{\mathrm{d}}\right)$, regional wind speeds $\left(\mathrm{V}_{\mathrm{R}}\right)$, and other relevant considerations to assist in designing and building structures. AS/NZS 1170.2:2011 identify eight individual wind regions for Australia, with regionally specific $M_{d}$ and $V_{R}$ values which can be applied to calculate the directional wind speed. Given the vast expanse of Australia and various wind hazards in both cyclonic and non-cyclonic wind areas, it is essential to accurately quantify current and future wind risk that is representative of the local wind climate. As such, this study compares the $\mathrm{M}_{\mathrm{d}}$ component of the AS/NZS 1170.2:2011 standards for four wind regions (A1, A4, B and C), with observed wind data (4 stations per wind region) - see Figure 1 for more details. Findings suggest that the wind regions analysed do not adequately represent the wind climates of the stations considered within each wind region. For example, while AS/NZS 1170.2:2011 assume that the same directional wind multipliers should apply for Perth and Adelaide, we show that the prevailing direction of the strongest wind gusts ( $\geq 99.9^{\text {th }}$ percentile) varies considerably between stations. Using station data to model $M_{d}$ suggests that AS/NZS 1170.2:2011 can underestimate wind risk for region A1 (70\% of cases) and overestimate between $62-77 \%$ of cases for regions A4, B and C. These results highlight some inadequacies with AS/NZS 1170.2:2011 and suggests more regionally-specific wind direction multipliers that are more indicative of local wind climates are required.
\end{abstract}

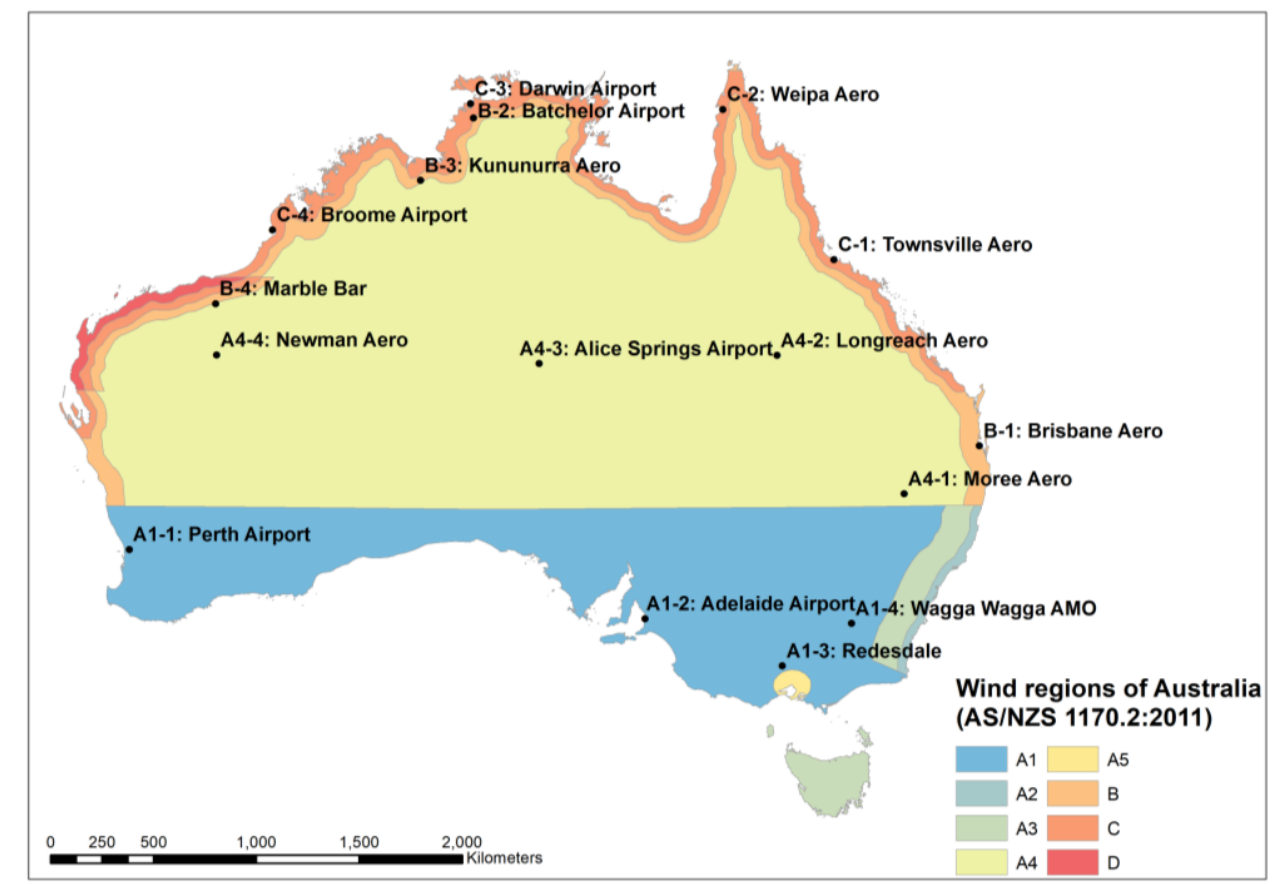

Figure 1. Location of Bureau of Meteorology (BOM) weather stations used for analysis from wind regions $\mathrm{A} 1, \mathrm{~A} 4, \mathrm{~B}$ and $\mathrm{C}$.

Keywords: Wind hazards, wind extremes, AS/NZS 1170.2:2011, Building Code of Australia (BCA) 


\section{INTRODUCTION}

In Australia, wind hazards vary according to location and include both mesoscale (thunderstorms and tornadoes) and synoptic-scale wind events (tropical cyclones, mid-latitude and extratropical cyclones, including East Coast Lows). Regardless, extreme wind events pose a significant threat to properties, lives and infrastructure. When considering the construction of a new development, or redevelopment of an existing structure in Australia, the Australia/New Zealand Standards for Wind Actions (AS/NZS 1170.2:2011; herein "standards"), outline the requirements to ensure the structural integrity from extreme winds. Typically, residential structures are built to withstand winds assessed to have a return period of 500 years (Stewart 2015). For Australia, eight individual wind regions are identified and include directional multipliers $\left(\mathrm{M}_{\mathrm{d}}\right)$ and regional wind speeds $\left(\mathrm{V}_{\mathrm{R}}\right)$ up to a 1-in-2500 year event, which should be applied to calculate the directional wind speed. Each wind region should adequately represent the wind climatology of each respective location, as $\mathrm{M}_{\mathrm{d}}$ should recognise the prevailing direction of the strongest winds.

Large areas of Australia are designated the same wind region (e.g. Region A1 in Figure 1), where the wind climate is considered the same in Perth (WA) as it is in Adelaide (South Australia; SA). The largest wind region (Region A4), covers the majority of the nation and straddles inland WA, Northern Territory (NT), Queensland (QLD), SA and New South Wales (NSW). For these examples, the standards assume the same wind climate, including $\mathrm{M}_{\mathrm{d}}$ and $\mathrm{V}_{\mathrm{R}}$ for every location in each respective wind region.

With climate change, the characteristics of our extreme weather systems are also expected to change (Walsh et al. 2016; Abbs 2012), highlighting the need to respond and derive more granular wind regions that reflect the wind climatology of that area and how it is projected to change (Sanabria and Cechet 2012). This study aims to assess whether current wind regions for Australia sufficiently represent the wind climatology of each location within each wind region by comparing the standards with observed data from 16 Bureau of Meteorology (BOM) across four wind regions (A1, A4, B and C).

\section{DATA}

For this study, four wind regions (A1, A4, B and C) have been chosen for further analysis as they cover a large geographic area, straddle both the coastline and interior of the majority of Australia and represent both cyclonic and non-cyclonic wind regions (see Figure 1). In particular, wind region A1 spans southwest and southern WA, a large portion of SA and NSW, and the majority of Victoria (VIC). Wind regions B and C wrap around the coastline (and up to $150 \mathrm{~km}$ inland) and include NSW, the entire coastal extent of QLD and NT and a large portion of WA. Comparatively, wind regions A2, A3, A5 and D are relatively small, and stations from these locations are not included in this analysis.

Sixteen Bureau of Meteorology (BOM) stations were analysed in this study (four per wind region; see Figure 1; Table 1). Both maximum 1-minute wind gusts and wind direction were analysed for each of the $16 \mathrm{BOM}$ sites. As this study focuses on extreme wind events, 1-minute wind data is analysed (instead of daily) for the following reasons: (i) so wind events can be analysed in their entirety and that multiple extreme wind events that occur within a 24-hour period can be considered, and (ii) so diurnal wind variability can be captured and considered in calculating predominant wind directions and $\mathbf{M}_{\mathrm{d}}$. Although using daily data would result in a longer period within which to analyse station data, this represents a trade-off between data length and temporal resolution, of which the latter is important for extreme wind events.

Table 1. Bureau of Meteorology weather stations used in this analysis

\begin{tabular}{|l|l|l|l|l|l|l|l|}
\hline $\begin{array}{l}\text { Wind } \\
\text { Region }\end{array}$ & Station ID & BOM Station Name & $\begin{array}{l}\text { Station } \\
\text { Number }\end{array}$ & Latitude & Longitude & Start date & End date \\
\hline \multirow{4}{*}{ A1 } & A1-1 & Perth Airport & 009021 & -31.9275 & 115.9764 & $01 / 10 / 1997$ & $31 / 1 / 2019$ \\
\cline { 2 - 7 } & A1-2 & Adelaide Airport & 023034 & -34.9524 & 138.5196 & $04 / 12 / 2001$ & $31 / 1 / 2019$ \\
\cline { 2 - 7 } & A1-3 & Redesdale & 088051 & -37.0194 & 144.5203 & $13 / 8 / 2007$ & $31 / 1 / 2019$ \\
\cline { 2 - 7 } & A1-4 & Wagga Wagga AMO & 072150 & -35.1583 & 147.4575 & $22 / 2 / 2000$ & $31 / 1 / 2019$ \\
\hline \multirow{4}{*}{ A4 } & A4-1 & Moree Aero & 053115 & -29.4898 & 149.8471 & $25 / 10 / 2001$ & $31 / 1 / 2019$ \\
\cline { 2 - 7 } & A4-2 & Longreach Aero & 036031 & -23.4397 & 144.2828 & $08 / 11 / 2001$ & $31 / 1 / 2019$ \\
\cline { 2 - 7 } & A4-3 & Alice Springs Airport & 015590 & -23.7951 & 133.8890 & $09 / 4 / 2003$ & $31 / 1 / 2019$ \\
\cline { 2 - 7 } & A4-4 & Newman Aero & 007176 & -23.4167 & 119.7992 & $21 / 5 / 2009$ & $31 / 1 / 2019$ \\
\hline \multirow{4}{*}{ B } & B-1 & Brisbane Aero & 040842 & -27.3917 & 153.1292 & $20 / 3 / 2000$ & $31 / 1 / 2019$ \\
\cline { 2 - 7 } & B-2 & Batchelor Airport & 014272 & -13.0544 & 131.0252 & $08 / 10 / 2009$ & $31 / 1 / 2019$ \\
\cline { 2 - 7 } & B-3 & Kununurra Aero & 002056 & -15.7814 & 128.7100 & $13 / 11 / 2010$ & $31 / 1 / 2019$ \\
\cline { 2 - 7 } & B-4 & Marble Bar & 004106 & -21.1756 & 119.7497 & $28 / 10 / 2010$ & $31 / 1 / 2019$ \\
\hline \multirow{4}{*}{ C } & C-1 & Townsville Aero & 032040 & -19.2483 & 146.7661 & $11 / 9 / 2001$ & $31 / 1 / 2019$ \\
\cline { 2 - 7 } & C-2 & Weipa Aero & 027045 & -12.6778 & 141.9208 & $03 / 2 / 2004$ & $31 / 1 / 2019$ \\
\cline { 2 - 7 } & C-3 & Darwin Aero & 014015 & -12.4239 & 130.8925 & $29 / 11 / 2001$ & $31 / 1 / 2019$ \\
\cline { 2 - 7 } & C-4 & Broome Airport & 003003 & -17.9475 & 122.2352 & $16 / 10 / 2002$ & $31 / 1 / 2019$ \\
\hline
\end{tabular}




\section{METHODOLOGY}

In this analysis, we calculate the probability of 1-minute wind gusts according to each cardinal direction for 16 BOM stations and calculate $\mathrm{M}_{\mathrm{d}}$ to compare with the standards. In doing so, the maximum 1-minute wind gust data is fitted using the peak-over-threshold (POT) methodology assuming a Generalised Pareto Distribution (GPD) (Palutikof et al. 1999; Sanabria and Cechet 2014; Holmes 2019). Following Holmes and Sanabria (2008), the following methodology is used to calculate $\mathrm{M}_{\mathrm{d}}$ using the observed BOM 1-minute wind data.

1. Only 1 -minute gust data $\geq 99.9^{\text {th }}$ percentile is included. For the purposes of this analysis, these winds are defined as 'extreme'.

2. Winds are fitted using the POT methodology assuming a GPD. Use of the POT method allows use of 1minute extreme winds. Using this methodology, the average crossing rate of the wind speed $\left(\mathrm{V}_{\mathrm{R}}\right)$ is:

$$
V_{R}=C-D\left(R_{I}\right)^{-k}
$$

Where $R_{I}$ refers to the average recurrence interval and $k$ (the shape factor), is fixed at 0.1 .

Then:

And:

$$
C=V_{0}+\frac{\sigma}{k}=V_{0}+\left(\frac{(1+k)}{k}\right) E
$$

$$
D=\frac{\sigma}{k}(\lambda)^{-k}=\left(\frac{1+k}{k}\right) E(\lambda)^{-k}
$$

Where $E$ is the average of all positive excesses above the given threshold and $\lambda$ is the rate of the crossing (number of crossings/number of years). Then, the mean excess $\left(E_{i}\right)$, above a specified threshold, $V_{i}$ is greater than $V_{0}$, which is given by:

$$
E_{i}=\frac{\sigma-k\left(V_{i}-V_{0}\right)}{1+k}
$$

Using a fixed factor $k=0.1$, an optimal least-squares fit of the straight line with known slope $(-k /(1+k)$, has an intercept on the $\left(\mathrm{V}_{\mathrm{i}}-\mathrm{V}_{0}\right)$ axis of $\hat{\sigma} /(1+k)$, where $\hat{\sigma}$ is

$$
\widehat{\sigma}=\bar{E}_{l}(1+k)+k * \overline{\left(V_{l}-V_{0}\right)}
$$

Where $\bar{E}_{l}$ is the average of the mean excesses over all $N$ thresholds, and $V_{i}$ is the mean of the increments of the $\mathrm{N}$ thresholds, $\mathrm{V}_{\mathrm{i}}$, above the lowest, $\mathrm{V}_{0}$.

3. Directional probabilities $\mathrm{p}(\theta)$ were calculated for $\geq 99.9^{\text {th }}$ percentile gusts according to eight cardinal wind directions (north, northeast, east, southeast, south, southwest, west and northwest)

4. Directional multipliers $\left(\mathrm{M}_{\mathrm{d}}\right)$ for eight cardinal directions were estimated by:

$$
M_{d}=\frac{C-D[100 * \mathrm{p}(\theta)]^{-k}}{C-D[50]^{-k}}
$$

Where C, D and $\mathrm{k}$ are parameters as calculated in Step 2. 


\section{RESULTS}

\subsection{Analysis of wind gust direction}

A summary of extreme winds highlights differences in the predominant wind gust direction between stations within the same wind region (Figure 2). For wind region A1, the predominant wind direction of the strongest wind gusts is from the east for station A1-1 (Perth Airport), from the west for stations A1-2 (Adelaide Airport) and A1-4 (Wagga Wagga AMO), and from the south for station A1-3 (Redesdale). Comparing the $\mathrm{M}_{\mathrm{d}}$ as per the standards suggests that for Region A1, the predominant wind direction of the strongest gusts is from the west, as winds from that direction are assigned the highest multiplier $\mathrm{M}_{\mathrm{d}}=1.00$. On the contrary, winds from the northeast, east and southwest are assigned the lowest multiplier $\mathrm{M}_{\mathrm{d}}=0.80$. For region A4, the standards suggest that the predominant winds are from the south, southwest and west, and are all allocated an $\mathrm{M}_{\mathrm{d}}=0.95$. However, for station A4-3 (Alice Springs Airport), the predominant wind direction is from the northwest and from the southeast for station A4-4 (Newman Aero).

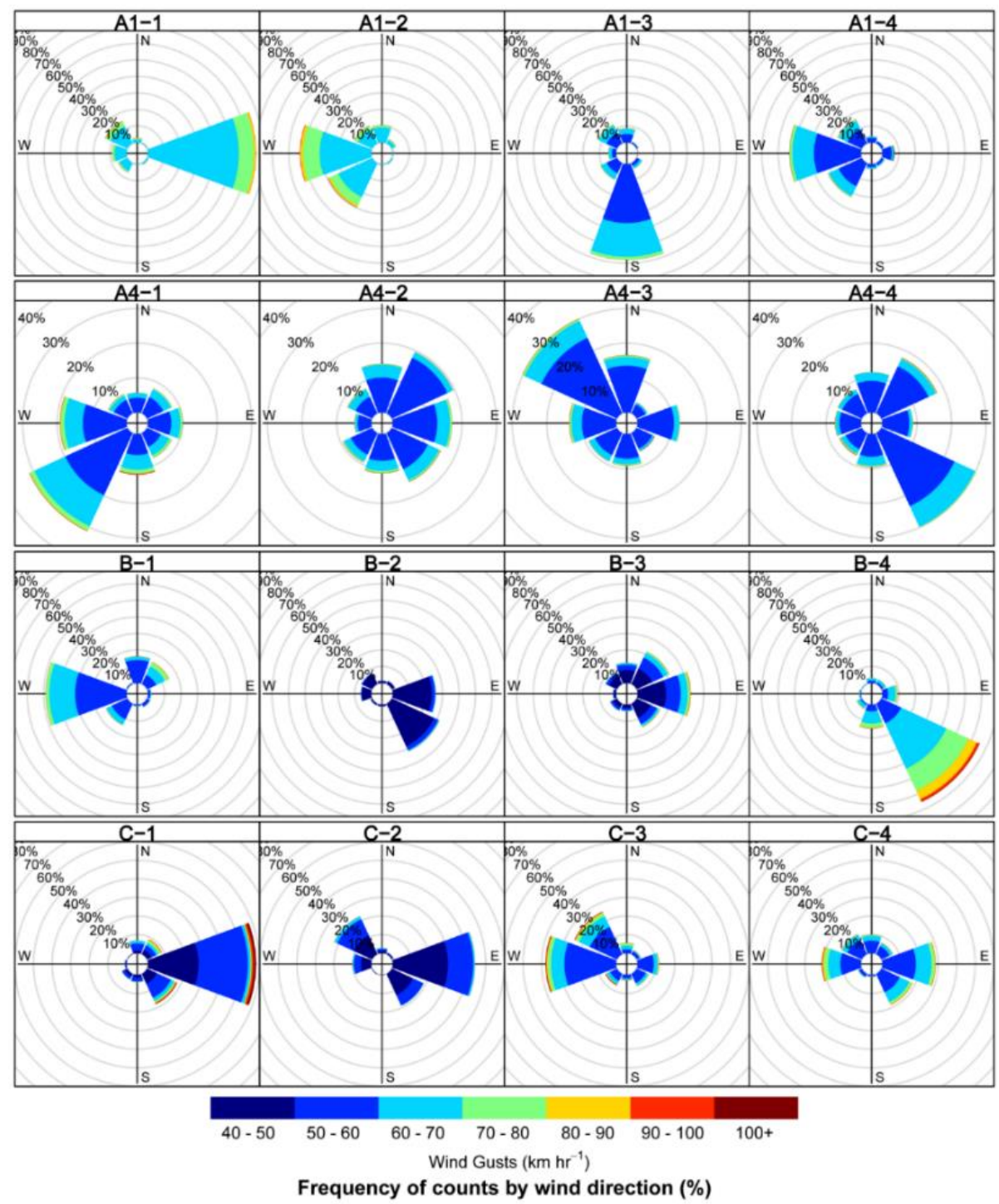

Figure 2. Wind rose summarising 1-minute maximum wind gusts $(\mathrm{km} / \mathrm{hr}) \geq 99.9$ th percentile for 16 Bureau of Meteorology (BoM) stations across A1, A4, B and C wind regions.

For wind regions $\mathrm{B}$ and $\mathrm{C}$, the standards apply $\mathrm{M}_{\mathrm{d}}=0.95$ for all cardinal wind directions. As explained by Yang et al. (2014), this is because the prevailing direction of wind gusts from tropical cyclones (TCs) and thunderstorms are small. However, $\geq 99.9^{\text {th }}$ percentile wind gusts for the eight stations analysed in wind regions $\mathrm{B}$ and $\mathrm{C}$ suggest extreme gusts prevail from different directions, e.g. mainly from the southeast for station B-4 
(Marble Bar), from the east for station C-1 (Townsville Aero) and from the west for station C-3 (Darwin Airport).

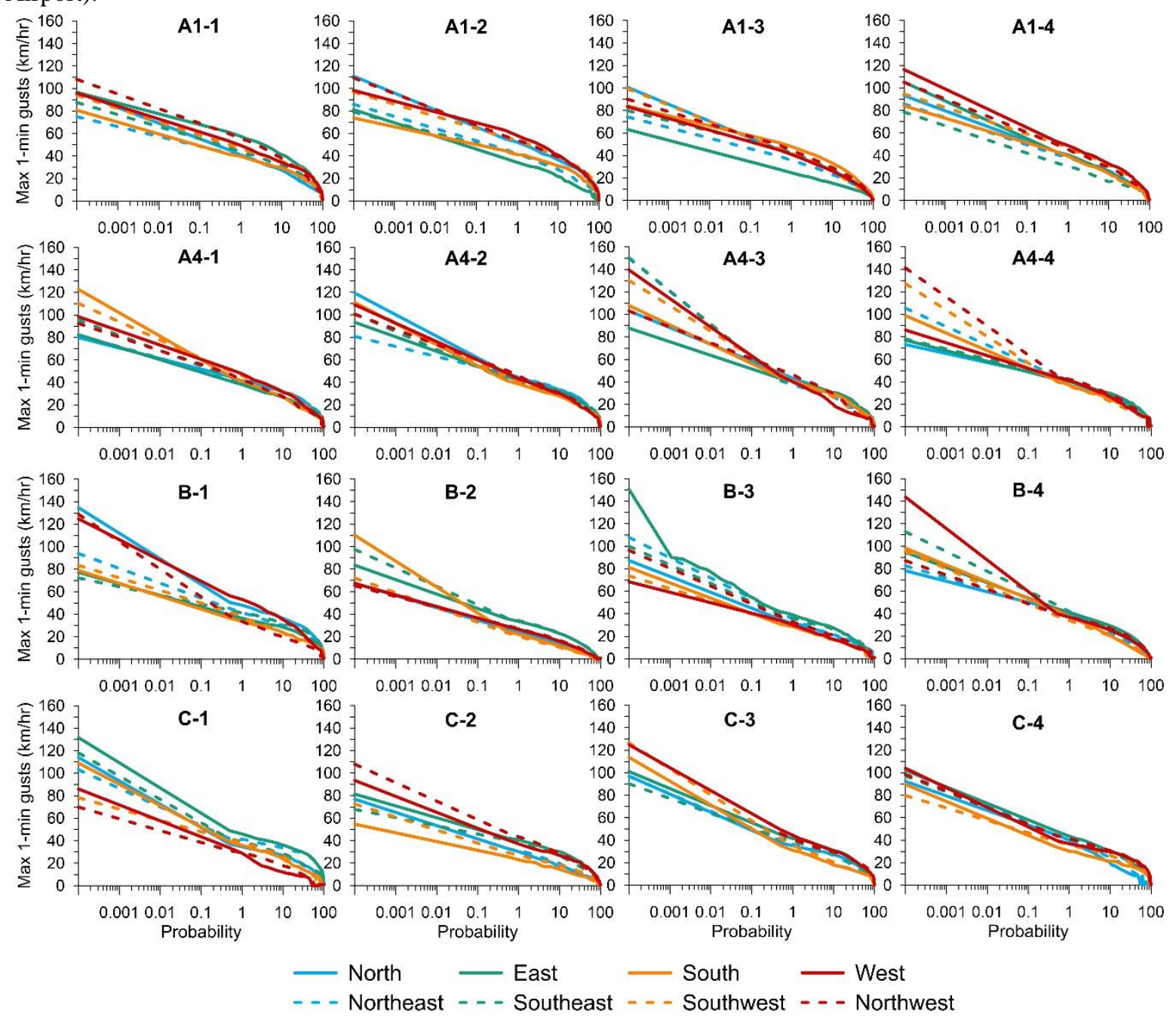

Figure 3. Probability of directional maximum 1-minute wind gusts for 16 Bureau of Meteorology (BOM) stations across $\mathrm{A} 1, \mathrm{~A} 4, \mathrm{~B}$ and $\mathrm{C}$ wind regions.

Comparing the probability of 1-minute wind gusts according to cardinal wind direction highlights considerable disparity between extreme 1-minute wind gusts (probabilities $\leq 0.01 \%$ ) and wind direction between stations and wind regions (Figure 2). For wind region A4, the most extreme winds for station A4-3 (Alice Springs Airport) were from the northeast/east (155-157 km/hr), while for station A4-4 (Newman Aero), maximum wind gusts were from the southwest $(126 \mathrm{~km} / \mathrm{hr})$. For wind regions B and C, substantial differences are observed for the magnitude of extreme gusts according to wind direction, e.g. for station B-3 (Kununurra Aero), maximum gusts from the east $(132 \mathrm{~km} / \mathrm{hr})$ were notably higher than maximum gusts from the west $(68 \mathrm{~km} / \mathrm{hr})$.

The lack of agreement between predominant wind directions (Figure 2) and the cardinal direction of the most extreme winds (Figure 3) between stations within the same wind regions is noteworthy. The extent of the differences in predominant wind directions are likely driven by the mesoscale and synoptic-scale weather systems that influence each respective station. The large spatial extent of many of the wind regions analysed means it is impossible to capture these comparatively small-scale (but important) regional influences. As such, the following analysis uses observational data and the POT methods by assuming a GPD, to calculate $\mathrm{M}_{\mathrm{d}}$ for each station.

\subsection{Calculation of directional wind multipliers using observational data and comparison with AS/NZS 1170.2:2011 standards}

Figure 4 compares the modelled $\mathrm{M}_{\mathrm{d}}$ calculated using observed station data with $\mathrm{M}_{\mathrm{d}}$ as outlined in the standards. This comparison reveals significant inconsistencies particularly for wind region A1, here the standards 
underestimate $\mathrm{M}_{d}$ (compared to modelled $\mathrm{M}_{\mathrm{d}}$ ) in $66 \%$ of cases, with a maximum (mean) variance of $26 \%$ (4\%). Station A1-1 (Perth Airport) sees the largest deviance between directional wind multipliers, where the standards underestimate multipliers up to $20 \%$ for winds from the east. Standards also underestimate $\mathrm{M}_{\mathrm{d}}$ up to $12 \%$ for wind from the northeast (Station A1-2; Adelaide Airport), up to $16 \%$ for winds from the south (Station A1-3; Redesdale) and up to $12 \%$ for winds from the east for station A1-4 (Wagga Wagga AMO). While the largest modelled $\mathrm{M}_{\mathrm{d}}$ are assigned to winds from the west for Adelaide Airport $\left(\mathrm{A} 1-2 ; \mathrm{M}_{\mathrm{d}}=1.00\right)$ and Wagga Wagga AMO $\left(\mathrm{M}_{\mathrm{d}}=0.98\right)$ and correspond with the largest directional multiplier for region A1 as per the standards $\left(\mathrm{M}_{\mathrm{d}}=1.00\right)$, the variance between other cardinal wind directions and stations is noteworthy.
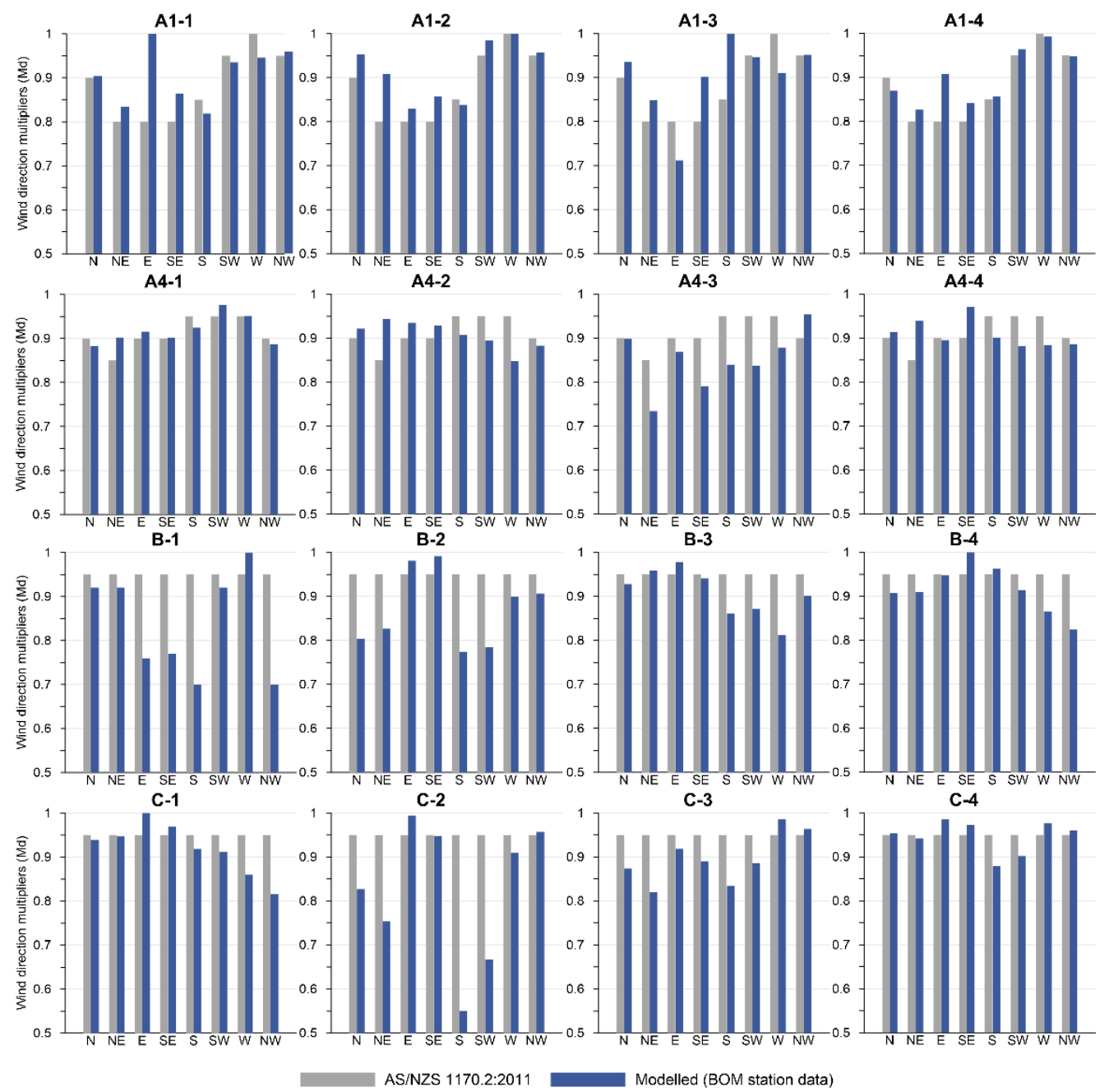

Figure 4. Comparison of AS/NZS 1170.2:2011 directional multipliers $\left(\mathrm{M}_{\mathrm{d}}\right)$ and observed $\mathrm{M}_{\mathrm{d}}$ for eight cardinal directions at $16 \mathrm{BOM}$ stations across $\mathrm{A} 1, \mathrm{~A} 4, \mathrm{~B}$ and $\mathrm{C}$ wind regions.

Compared to wind region A1 (30\% of cases overestimated), $\mathrm{M}_{\mathrm{d}}$ as per the standards is more likely to be overestimated for wind regions A4 (56\%), B (78\%) and C (69\%). Considerable overestimation is observed for station C-2 (Weipa Aero), where winds from the south produced a modelled $\mathrm{M}_{\mathrm{d}}=0.55$, compared to the standards where $M_{d}=0.95$ is recommended ( $42 \%$ overestimation). Substantial variability in modelled $M_{d}$ between wind directions is also observed in wind regions $\mathrm{B}$ and $\mathrm{C}$.

\section{DISCUSSION AND CONCLUSIONS}

For a given location, the accurate reporting of wind risk is an essential consideration for a range of applications, including the construction of new structures and/or modification of existing structures. However, this study has identified that differences between what the standards suggest and what observations show mean that broad generalisations surrounding local wind climatology are made. In this analysis, we show that for extreme wind gusts $\left(\geq 99.9^{\text {th }}\right.$ percentile), predominant wind directions and maximum 1-minute wind gusts vary markedly between stations within the same wind region. For example, the same $M_{d}$ and $V_{R}$ apply to Perth Airport (A11), Adelaide Airport (A1-2) and Redesdale (A1-3), however analysis has shown that predominant extreme 
winds are from the east, west and south respectively. In addition, the magnitude and cardinal direction of the strongest winds are also variable. Also, many regional and rural communities in Australia are considered to have the same wind climate as coastal regions. This is potentially problematic given the significant amount of infrastructure to support natural resource operations in these regions.

Calculation of $\mathrm{M}_{\mathrm{d}}$ for $16 \mathrm{BOM}$ stations suggests that the standards typically underestimate the multipliers for region $\mathrm{A} 1$ (66\% of cases) and overestimate $\mathrm{M}_{\mathrm{d}}$ in $56 \%$ (region $\mathrm{A} 4$ ), $78 \%$ (region $\mathrm{B}$ ) and $69 \%$ (region $\mathrm{C}$ ) of cases. Individual cases can see variance between the standards and modelled $\mathrm{M}_{\mathrm{d}}$ of up to $42 \%$ (southerly winds for Station C-2; Weipa Aero). For regions impacted by cyclonic winds (regions B and C), the value of $\mathrm{M}_{\mathrm{d}}=$ 0.95 applied to all regions, means that in most cases, the standards typically overestimate modelled $\mathbf{M}_{\mathrm{d}}$. However, this raises an interesting question about balancing safety considerations with the financial implications and complications associated with 'over-design' (Palutikof et al. 1999). The contrasts observed in predominant wind gust directions and $\mathrm{M}_{\mathrm{d}}$ between stations within common wind regions suggests that the current approach may result in an underestimation or overestimation of potential risk. Importantly, as the magnitude of extreme wind gusts increases, the differences in the directional wind speed also increase. While the brevity of available 1-minute wind gust data was limited at some sites, it is still useful in understanding how the observed wind conditions compare with the standards.

There is a significant opportunity to derive more granular, regionally specific information that is representative of the local wind climate. Doing so may identify areas where current $\mathbf{M}_{d}$ are inadequate and will re-assign $\mathbf{M}_{d}$ based on the characteristics of the local wind climate, with an appropriate safety margin. High-resolution (spatial and temporal) gridded wind data (e.g. hourly reanalysis data from the European Centre for MediumRange Weather Forecasts (ECMWF) coupled data assimilation system for climate reanalysis (CERA-20C) (Laloyaux et al. 2018)) could be used to characterise local wind climates in conjunction with observational data. In addition, outputs from climate models could be used to understand how present and future risk may differ (see Sanabria and Cechet (2014)). Doing so would facilitate the calculation of design estimates that account for projected changes in future extreme wind events.

In this study, we have shown inconsistencies between $\mathrm{M}_{\mathrm{d}}$ when comparing the AS/NZS 1170.2:2011 standards with observational data. Comparing observed data within each wind region (A1, A4, B and C), suggests that the standards do not represent the full extent of local wind variability. An opportunity exists to revisit AS/NZS 1170.2:2011 to derive locally specific wind regions for Australia. Doing so would allow re-evaluation of wind risk, which could also incorporate possible future changes to wind risk (i.e. the changing nature of tropical cyclone activity). Improved quantification of regional wind climatology will also enable improved post extreme wind event analysis for local councils, practitioners, engineers and consultants.

\section{ACKNOWLEDGEMENTS}

The authors would like to thank John Holmes (JDH Consulting) for his advice in calculating the wind direction multipliers $\left(\mathrm{M}_{\mathrm{d}}\right)$ using observed wind data.

\section{REFERENCES}

Abbs, D., 2012: The impact of climate change on the climatology of tropical cyclones in the Australian region. 16 pp pp.

Holmes, J., and L. A. Sanabria, 2008: Directional Extreme Winds in the Geelong area. AMOS National Conference and AWES Workshop, Jan. 29-Feb. 1 2008, Geelong, Vic.

Holmes, J. D., 2019: Extreme Wind Analysis and Prediction - Fitting methods using the PoT/GPD approach with a fixed shape factor. $14 \mathrm{pp}$.

Laloyaux, P., and Coauthors, 2018: CERA-20C: A Coupled Reanalysis of the Twentieth Century. J. Adv. Model. Earth Syst., 10, 1172-1195, doi:10.1029/2018MS001273.

Palutikof, J. P., B. B. Brabson, D. H. Lister, and S. T. Adcock, 1999: A review of methods to calculate extreme wind speeds. Meteorol. Appl., 6, 119-132, doi:10.1017/S1350482799001103.

Sanabria, L. A., and R. P. Cechet, 2012: Calculation of Wind Direction Multipliers using Climate Simulated Data. 15th Australasian Wind Engineering Society Workshop, Sydney, NSW, Australia.

Stewart, M. G., 2015: Risk and economic viability of housing climate adaptation strategies for wind hazards in southeast Australia. Mitig. Adapt. Strateg. Glob. Chang., 20, 601-622, doi:10.1007/s11027-013-9510-y.

Walsh, K., and Coauthors, 2016: Natural hazards in Australia: storms, wind and hail. Clim. Change, doi:10.1007/s10584-016-1737-7. http://link.springer.com/10.1007/s10584-016-1737-7.

Yang, T., K. Nadimpalli, and B. Cechet, 2014: Local Wind Assessment in Australia Computation Methodology for Wind Multipliers. Geoscience Australia, Canberra. 